УДК 330.12

DOI: $10.14451 / 1.198 .138$

ГРНТИ 06.56.45

\title{
ПРОЦЕСС ФОРМИРОВАНИЯ И РАЗВИТИЯ СИСТЕМЫ ПРЕДОСТАВЛЕНИЯ ГОСУДАРСТВЕННЫХ УСЛУГ И ПОВЫШЕНИЕ ЭФФЕКТИВНОСТИ УПРАВЛЕНИЯ ЕЮ НА РЕГИОНАЛЬНОМ И МЕСТНОМ УРОВНЕ
}

\author{
(c) 2021 Санчес Родригес Виктор \\ аспирант кафедры Экономической теории и менеджмента \\ Московский педагогический государственный университет, Россия, Москва \\ E-mail: mariovictorsanchez2017@gmail.com
}

(c) 2021 Лихачев Михаил Олегович

доктор экономических наук, доцент, профессор кафедры Экономической теории и менеджмента

Московский педагогический государственный университет, Россия, Москва

Главный научный сотрудник Центр научно-информационных исследований по науке, образованию и технологиям

Институт научной информации по общественным наукам (ИНИОН) РАН, Россия, Москва

E-mail: olegmix71@mail.ru

В статье исследуется процессы трансформации современной системы предоставления государственных услуг и рассматривается эволюция теоретических и практических подходов к управлению этой системой и повышению уровня эффективности ее функционирования на различных уровнях системы государственной власти в условиях развития в этой сфере рыночных тенденций и влияния процессов глобализации мировой экономики.

Ключевые слова: государственный сектор, услуги, смешанная экономика, общественные блага, рынок государственных услуг, конкуренция, монополия

Современное развитие открытого, гибкого сектора государственных услуг, ориентированного на сотрудничество и взаимодействие с частным сектором экономики, признано одним из главных приоритетов для большинства стран мира [1; 7]. Расширение и углубление процессов глобализации, а также внедрение электронного администрирования создают возможность существенного повышения эффективности удовлетворения спроса на государственные услуги со стороны граждан и хозяйствующих субъектов, повышение мобильности их предоставления на региональном и местном уровне [5; 8].

Мировая практика показывает, что в условиях современной смешанной экономики высокий уровень качества государственных услуг является ключевым фактором, позволяющим обеспечить открытость и прозрачность в деятельности органов власти, укрепить доверие населения и создать новые конкурентные преимущества для региона или даже целой страны [4].

В тоже время в странах с трансформационной экономикой главной проблемой развития государственного сектора услуг является то, что органы региональной власти и местного само- управления из-за целого ряда объективных и субъективных факторов не всегда способны надлежащим образом обеспечить предоставление качественных услуг населению [3].

Специфика государственных услуг как объекта экономической деятельности

Государственные услуги - это услуги, предлагаемые местным, государственным или федеральным правительством либо непосредственно через предоставление государственного сектора, либо косвенно через государственное финансирование предоставления частных услуг. Примеры государственных услуг, предлагаемых непосредственно местными, государственными или федеральными правительствами, которые являются основой для сбора данных в любом исследовании, посвященном государственным услугам, включают государственное образование, управление водоснабжением и военную защиту. Примеры государственных услуг, предлагаемых косвенно через государственное финансирование частных услуг, включают субсидии на здравоохранение, и финансовую помощь для покрытия расходов на высшее образование. Государственные услуги характеризуются тем, 
что они финансируются налогоплательщиками и, по сравнению с частными товарами, имеют низкую степень конкурентности в потреблении и исключаемости [4].

К числу специфических особенностей государственных услуг можно отнести следующие:

Во-первых, в отличие от чисто рыночных товаров и услуг, для государственных услуг характерно преобладание косвенной оплаты и использования механизмов частичного или полного субсидирования. Потребитель, как правило, не оплачивает полную стоимость государственной услуги, оплата производится за счет государственного финансирования, источником средств для которого являются налоговые поступления, взимаемые со всего населения. При этом имеет место значительное перекрестное субсидирование, в результате которого финансово обеспеченные граждане и/или редкие потребители данных услуг частично оплачивают потребление малообеспеченных граждан и/или регулярных потребителей [6; 9].

Во-вторых, конкурентность между организациями, предоставляющими государственные услуги, является крайне низкой. Потребители имеют, как правило, крайне ограниченный выбор между организациями, предоставляющими государственные услуги определенного типа, либо вовсе не имеют такого выбора [2; 10].

В-третьих, для значительной доли государственных услуг характерно, так называемое, необходимое или навязанное потребление. Потребление этих услуг определенными группами граждан либо является необходимым для поддержания их благосостояния на минимально приемлемом для общества уровне, либо напрямую предписаны законодательными и нормативными актами государственных органов.

B-четвертых, предоставление государственных услуг связано с определенным их восприятием с точки зрения норм общественной морали. Современное общество исходит из представления о том, что одной из важнейших функций государства является обеспечение граждан теми видами необходимых жизненных благ и услуг, которые не предоставляются рыночной системой или предоставляются в недостаточном количестве. В основе этой функции лежат нормы общественной морали, получившие всеобее признание во второй половине XX в. и ставшие основой для оценки эффективности деятельности современных государств.
B-пятых, в сфере потребления государственных услуг потребитель, в отличие от сферы потребления рыночных благ и услуг, выступает в двойной роли. С одной стороны, он является непосредственным получателем услуги и как таковой является классическим потребителем. С другой стороны, он является гражданином, который через систему налогообложения частично оплачивает предоставление этих услуг как самому себе, так, возможно, другим потребителям.

Поэтому спрос на государственные услуги проявляет себя особым образом - через участие граждан в деятельности государственных структур и общественных организаций, которые отстаивают проведение определенной политики в сфере оказания государственных услуг. В силу этого, объемы и структура потребления государственных услуг является объектом не индивидуального, а общественного выбора. При этом, в процессе потребления государственных услуг, возникает серьезная проблема идентификации конечного потребителя, поскольку в значительном числе случаев субъекты несущее основное бремя оплаты не являются теми лицами, которые являются основными их потребителями. Это создает поле для социальных конфликтов и многократно усложняет проблему общественного выбора.

Особенности процесса предоставления государственных услуг

Процесс предоставления государственных услуг имеет ряд особенностей:

Во-первых, характер финансирования государственного сектора является коллективистским, поскольку центральный орган (правительство) выбирает, как налоговые доходы распределяются между различными услугами, предоставляемыми им. Другими словами, каждый гражданин вносит деньги через налоги на финансирование всех государственных услуг, независимо от того, использует ли он каждую услугу и в какой степени, и полная оплата конкретной использованной услуги, как правило, уже произошла до оказания этой услуги и по цене, которая была субсидирована. другими налогоплательщиками, которые сами могут использовать или не использовать эту услугу. Сложность усугубляется тем, что индивидуальное производство государственных услуг не может быть фактически одобрено налогоплательщиками на индивидуальном уровне.

Во-вторых, за некоторыми исключениями, 
у потребителей не так много альтернатив для потребления услуг, предоставляемых в государственном секторе. Оценка затрат на переход и доступность сравниваемых продуктов является важным фактором в исследованиях удовлетворенности потребителей. Хотя в современном мире возникли частные компании, которые конкурируют с определенными услугами, такими как почтовая доставка, здравоохранение, местная безопасность и образовательные услуги, однако, значительная часть государственных услуг по-прежнему остается вне сферы действия конкуренции. Таким образом, у потребителей нет выбора, как потреблять большую часть услуг, предоставляемых государством.

В-третьих, у потребителей зачастую также нет выбора, включать ли относительно более высокую или низкую долю государственных услуг в структуру своего потребления. Например, для большинства людей стремящихся реализовать свой человеческий капитал посредством работы по найму и желающим получать доход в виде заработной платы, необходимо либо получить водительские права, либо использовать услуги общественного транспорта, чтобы добираться до работы. Также необходимо в государственных структурах весь необходимый пакет документов для легального трудоустройства. Безусловно, услуги частного сектора также удовлетворяют потребности потребителей. Однако в отличие от частных услуг, большая часть государственных услуг используется по необходимости.

В-четвертых, как уже было сказано выше, предоставление услуг государственного сектора основано на принятом современной общественной моралью представлении о том, что основная функция государства состоит в чтобы обеспечить удовлетворение частных и общественных потребностей в ситуации когда частный сектор не может удовлетворить эти потребности в полной мере или соответствующие частные блага являются недоступными для значительного числа граждан. Поскольку многие государственные услуги являются общественными благами, они как правило либо не предоставляются совсем, либо предоставляются в недостаточном количестве в тех случаях, когда их производство доверено частному сектору. Кроме того, оказание некоторых государственных услуг связано с таким огромным положительным эффектом масштаба, что делает их объектом естественной монополии, поскольку производство их в усло- виях конкурентного рынка является чрезмерно дорогостоящим по сравнению с производством в условиях монополии. Как известно, наиболее рациональным решением проблемы потенциальной нехватки общественных благ является их принудительное производство за счет введенных государством налогов, покрывающих, возникающие при таком производстве затраты. Однако в отличие от традиционного экономического обоснования, согласно которому общественные блага характеризуются неконкурентностью и неисключаемостью, большинство услуг, предоставляемых современными правительствами, не обладают этими характеристиками. В действительно, они предоставляются в государственном секторе из-за распространенного морального убеждения в том, что определенные услуги, такие как индивидуальное здравоохранение и субсидируемое жилье, являются универсальными правами человека.

Пятая особенность предоставления услуг в государственном секторе тесно связана с уже упоминавшимися моральными убеждениями о правах человека, но также с рассмотрением человеческой личности как общественной ценности и как части совокупного человеческого капитала общества. Она основана на представлении о том, что потребители государственных услуг не просто потребляют услуги ради своей личной ценности, но они потребляют их в рамках своей двойственной роли как потребителей и как членов общества. В самом деле, если услуги государственного сектора предоставляются за счет общественных средств, потому что они считаются жизненно важными услугами для граждан либо полезными с точки зрения общего блага, то есть повышения общественного благосостояния, то процесс их потребления увеличивает как частную, так и общественную ценность. Получается, что «ценность, услуг, предоставляемых государством, «потребляется» как гражданами (поскольку в результате увеличивается общественная ценность), так и частными клиентами (поскольку в результате возрастает их частное благосостояние)» Алфорд (2002). При этом в качестве граждан-потребителей и частных клиентов выступают одни и те же лица.

Хотя двойственная роль частного потребителя и гражданина государства, постоянно присутствует в потреблении государственных услуг, еще одним моментом, отличающим государственные услуги от услуг частного сектора, 
является то, что их производство, по-видимому, в основном определяется гражданской ролью потребителя. Частные товары и услуги, даже в некоммерческом секторе, производятся в результате таких рыночных факторов, как спрос, прибыльность и реализация инноваций. Однако масштабы потребления государственных услуг определяются преимущественно избирателямигражданами, которые принимают во внимание как частную, так и общественную ценность услуг государственного сектора.

И, наконец, важным аспектом потребления государственных услуг является сложившееся представление о том, что их потребителя часто трудно идентифицировать. В частности, это имеет место в тех случаях если услуга обладает высокой степенью неисключаемости и доступности, например, национальная оборона, охрана правопорядка, снабжение чистой водой, ремонт улиц и удаление отходов (и это лишь некоторые примеры), то непосредственно идентифицировать всех конечных пользователей этих услуг, а тем более косвенных бенефициаров, практически невозможно. Действительно, многие государственные услуги не оплачиваются на основе рыночных транзакций, и гражданскому пользователю, возможно, не потребуется напрямую взаимодействовать с государственной организацией, чтобы использовать эту услугу. Таким образом, прямую ценность определенных услуг государственного сектора с точки зрения их круга пользователей-граждан может быть очень трудно определить.

Критерии оценки качества предоставления государственных услуг

Несмотря на все проблемы, связанные с оценкой стоимости и полезности, извлекаемой из потребления государственных услуг конечными потребителями и внешними бенефициарами, государственные услуги можно оценить надлежащим образом ряду параметров.

Во-первых, это степень обеспеченности процесса оказания услуг материальными активами, что включает в себя помимо обеспеченности материальными средствами и оборудование, внешний вид персонала.

Во-вторых, надежность, то есть способность точно и надлежащим образом оказать соответствующую услугу.

В-третьих, постоянная готовность оказать клиентам услуги установленной номенклатуры и качества и оперативность обслуживания.
В четверных, уверенность, знания и вежливость сотрудников, а также их способность внушать доверие.

В пятых, сочувствие, заботливое, индивидуальное внимание, которое организация, оказывающая государственные услуги должна демонстрировать своим потребителям.

Однако, необходимо также учитывать, что государственные услуги обладают определенными отличительными характеристиками, которые могут способствовать другим аспектам оценки в общей суммарной оценке качества государственных услуг потребителями. Большинство из этих отличий основаны на том общем представлении, что государственные услуги оказываются централизованно и финансируются за счет общих налоговых поступления, взимаемых из доходов всех членов общества. Поэтому процесс оказания этих услуг и его результаты должны находиться под контролем и получать соответствующую оценку со стороны представителей гражданского общества. А представители гражданского общества, исходя из своих специфических потребностей могут оценивать качество предоставляемых государством услуг по самым разным критериям и параметрам, отражающим как уникальные характеристики самих этих услуг, так и специфические характеристики самих общественных потребностей.

Развитие системы предоставления государственных услуг как объекта управления

Ключевым процессом развития сектора государственных услуг, как объекта управления на региональном и местном уровне, является децентрализация, которая предусматривает делегирование органам местной власти полномочий по предоставлению ряда наиболее востребованных гражданами услуг: регистрации бизнеса, прав на недвижимое имущество, места жительства, а также предоставление сведений из государственного земельного кадастра и т.д. [2].

Эффективным инструментом децентрализации является создание на региональном и местном уровнях центров предоставления государственных услуг. Актуальными проблемами обеспечения деятельности этих центров являются следующие: надлежащее обустройство помещений в удобных для жителей частях города; обеспечение доступа к центрам маломобильным группам населения; предложение сопутствующих услуг в помещении центров; расширение внедрения электронных сервисов. 
Среди факторов, которые имеют важное значение для развития и повышения качества государственных услуг на уровне местных властей, необходимо отметить следующие: рост профессионального уровня и политической ответственности глав местных государственных администраций и председателей органов местного самоуправления, осуществление мониторинга эффективности предоставления государственных услуг, приспособление сети центров предоставления услуг к потребностям объединенных территориальных общин.

Из числа инновационных направлений формирования и развития государственного сектора сферы услуг в региональном измерении можно отметить следующие: разработка моделей предоставления государственных услуг в комплексе или «одним пакетом», в зависимости от жизненных обстоятельств и бизнес-ситуаций; создание регионального контакт-центра по вопросам предоставления государственных услуг; введение единой многоканальной системы оценки качества обслуживания организации и учреждений, функционирующих в сфере предоставления государственных услуг; разработка и внедрение мобильных приложений региональных информационных систем в сфере предоставления административных услуг; введение нестандартных подходов к организации работы сервисных центров, как действенных площадок для всестороннего развития жителей региона.

Благодаря таким новациям в системе предоставления государственных услуг на качественно новый уровень выходят отношения между региональными органами власти, гражданами и бизнесом. Для координации своих действий государство получает максимально полные данные о позиции граждан, а последние имеют открытый доступ к официальной информации, возможность высказывать свои пожелания и следить за их выполнением, поддерживать реальный диалог с представителями власти в онлайн-режиме, лоббировать принятие важных законов или решений.

Подводя итоги всему сказанному выше можно сделать следующий вывод. Процесс формирования и развития государственного сектора сферы услуг, как объекта управления на региональном и местном уровне, предусматривает развитие системы сервисного обслуживания граждан и предприятий посредством максимального приближения услуг к каждому пользователю через внедрение современных электронных сервисов, что позволит стимулировать социально-экономическое развитием территории, формирование инфраструктуры открытых данных, телекоммуникационной среды и обеспечение равенства граждан независимо от места их проживания в соблюдении их конституционных прав.

\section{Библиографический список}

1. Батырева Д.Б. Повышение качества и доступности предоставления государственных и муниципальных услуг как приоритетное направление государственного управления Российской Федерации // Экономика и предпринимательство. 2019. № 7 (108). С. 93-97.

2. Зуева С.М., Осипова М.Ю. Инструментарий стратегического управления клиентоориентированным центром по оказанию государственных услуг // Там же. 2019. № 10 (111). С. 1063-1069.

3. Погодина И.В. Факторы, оказывающие негативное влияние на качество государственных услуг, Государственная власть и местное самоуправление. 2018. № 6. С. 23-25.

4. Потебня Н.В. Сущность системы управления государственными услугами // Colloquium-journal. 2019. № 26-9(50). С. 207-208.

5. Сидоренко Э.Л. Эффективность цифрового государственного управления: теоретические и прикладные аспекты // Вопросы государственного и муниципального управления. 2019. № 2. С. 93-114.

6. Челелева Н.А. Системный подход к управлению учреждениями здравоохранения // Инновации и инвестиции. 2019

7. Orellana A. G; Vega L.I; López F. C; Salas P. O. Plataforma cubana de Historias

8. Clínicas Digitales e Vitae. Concepción y metodología para su desarrollo //Convención Internacional de Salud, Cuba. 2018. http: //www.convencionsalud2018.sld.cu/index.php/connvencionsalud/2018/paper/viewFile/216/1005

9. Laing, A. Marketing in the public sector: Towards a typology of public services. // Marketing Theory, 2003, Vol. 3(4), pp. 427-445.

10. McFadyen, K., Harrison, J. L., Kelly, S. J., \& Scott, D. Measuring service quality in a corporatised public sector environment. // Journal of Nonprofit \& Public Sector Marketing, 2001, Vol. 9(3), pp. 35-51. 